\title{
Instructor Acceptance of Mobile Learning in Saudi Arabia: A Case Study of Hail University
}

\author{
O. Alharbi ${ }^{1}, H$. Alotebi $^{2}$, A. Masmali ${ }^{3} \& N$. Alreshidi $^{4}$ \\ ${ }^{1}$ University of Glasgow, Glasgow, UK \\ ${ }^{2}$ Cleveland State University, Cleveland, Ohio, USA \\ ${ }^{3}$ Kansas State University, Manhattan, KS, USA \\ ${ }^{4}$ University of Hail, Hail, KSA \\ Correspondence: O. Alharbi, University of Glasgow, Glasgow, UK. E-mail: king20014@hotmail.com
}

Received: March 6, 2017

doi:10.5539/ijbm.v12n5p27
Accepted: April 24, $2017 \quad$ Online Published: April 27, 2017

URL: https://doi.org/10.5539/ijbm.v12n5p27

\begin{abstract}
Mobile technology has influenced almost every aspect of our modern lives. The enhancement of learning in Saudi Arabia, as well as significant development in education overall, may be possible through mobile learning. However, the successful implementation of mobile learning in tertiary education profoundly relies on the acceptance of mobile learning from both students and instructors. Most mobile learning acceptance studies target higher education students. Therefore, this study aimed at examining the factors that affect university instructors' intentions to use mobile learning at Hail University. Eighty instructors completed the online survey, and the results indicated that performance experience, effort expectancy, social influence, and facilitating conditions altogether predicted the instructors' use of mobile learning, as $67 \%$ of the variation was found to be affected by these variables in the multiple regression analysis outcome. The results also suggested that effort expectancy is the best predictor of instructors' behavioural intentions to use mobile learning.
\end{abstract}

Keywords: Acceptance, Instructor, Mobile Learning, Technology

\section{Introduction}

The mobile learning and teaching environment is amongst the largest technologically and can be found within the scope of a growing understanding of this sector over the last ten years. Alongside the rise in access to information, online learning has improved enormously, resulting in advancement in both the research and design of accessible mobile learning applications. It is possible to argue that a mobile learning type could be described as a holistic tool providing tutoring for the contemporary market while also looking to the future. This research strives to fundamentally define what 'learning' means, and then measures the levels of acceptance by students studying in Saudi universities. The education policies in Saudi Arabia are driven by government policy that depends on Islamic cultural belief and regulation (MOE, 2016). It is therefore plausible to argue that strengthening mobile learning provision, in particular for tertiary education, would be a good idea where nearly three quarters of mobile users access smart phone devices (eMarketer, 2015).

It can be argued that mobile learning and teaching could help in the promotion of education policies in Saudi Arabia, which are founded on separating genders throughout each educational level. Under mobile learning, males and females could partake in exchanging and sharing knowledge with ease while not violating any restriction of religion and culture within the confining norms of Saudi society.

There is a definite gap in any in-depth studies on this topic in Saudi Arabia. Therefore, this research could be of significance for the Saudi Ministry of Higher Education by offering an insight into the future development of mobile learning and teaching and enhancing the skill set and understanding of students. The Saudi government could promote ideas around online learning education in several different ways. These might include establishing the concept of the long-distance university, which could accommodate a high number of students graduated from school in Saudi Arabia. This could also develop more advanced comprehension and use of mobile learning targeted at those who wish to extend their learning through mobile devices. Furthermore, mobile learning and teaching can aid students or teachers who may show an interest in mobile learning in order to identify and explore any individual requirement necessary for the learning approaches practiced to accept and adopt the Saudi 
Arabian universities and other academic institutes. The central discussion this study involves the ways in which teachers are influenced in their teaching, and acceptance of mobile learning and teaching in Saudi Arabian universities.

\subsection{Research Problem}

Mobile learning and teaching at university level is not widespread in Saudi Arabia, despite readily accessible wireless use (Nassoura, 2012). There is also little research on the intentions of teachers in this country to use mobile learning and teaching. This should be addressed, as it could enable Saudi universities to introduce appropriate mobile technology for teachers to promote. This certainly requires more in-depth research, given the limited use to date and the apparent lack of study into the modification and development of software and its use (Wang, Wu \& Wang, 2009). Therefore, further relevant study is important to ascertain how far the Unified Theory of Acceptance and Use of Technology (UTAUT) could highlight teachers' willingness to adopt mobile technology. The aims of this study are to consider any determinant that might indicate teachers' future use of mobile learning. This will be based on the UTAUT model put forward by Venkatesh, Morris, Davis and Davis (2003).

\subsection{The Benefits of Mobile Learning}

Across the educational sphere, mobile technology has been perceived as possessing several strengths, which have been outlined by the Quality Improvement Agency (2008). Firstly, rather than being obscured by PC screens in classrooms, hand-held technology will encourage the teacher and students to engage more. Secondly, PCs are large and require more space in a teaching environment, unlike mobile devices. Thirdly, laptops as well as paper-based resources and documents are all heavier and more cumbersome to transport compared to a tablet or PDA device with material electronically stored. Fourthly, a standard mouse and keyboard PC set up is not as natural as using a stylus pen on a handheld device. In addition, wireless technology such as Bluetooth, or PDA's infrared technology, can be used to transmit material rapidly and easily among a group, or a device can simply be passed from person to person, while software and email allows teachers and students to select and transfer text between documents; therefore, cooperative work is simpler.

Furthermore, practical learning is facilitated by mobile technology's transportability and ability to be used in an array of environments, whether in hotels, on public transport or in domestic settings. Even PlayStation Portable or Nintendo DS devices, as well as various other mobile and handheld technologies, could be utilised to renew a students' enthusiasm for learning interactively. Lastly, PCs can be expensive equipment, whereas PDAs and handheld technology require comparatively less expenditure, thus the digital divide may be narrowed. Such technology is also considerably more versatile, with nine university-level educational tasks aided by mobile devices, according to Kennedy et al. (2008): peer-to-peer calling; email communication; text service communication; video conferencing and calls; online research and service access; the use of mobile film and photo technology; using diary and contact lists for day-to-day organisation; storage of and listening to music; as well as distributing films and images to peers. Regardless of time or location, tasks can be worked on and interaction with others can take place through mobile learning, providing advantages to those adept with the technology. The Saudi Arabian university context for mobile learning, as well as learners' enthusiasm for such technology, is the focus of this study. Having outlined some of the strengths of m-learning, weaknesses will now be considered.

\subsection{Mobile Learning's Drawbacks}

Longer duration of searches, lower battery life, constrained processing power, handheld devices' restricted screen size, smaller memory, writing difficulties, low contrast, colour and resolution, restricted web access and poor download speeds are all issues related to mobile learning. Keypad and stylus technology for mobile devices can be awkward to use, screen size is restricted, while memory and battery limitations are also apparent (Cheun $\&$ Hew, 2009). Furthermore, screen size may be incompatible with websites, while online activity can be constrained by server power.

\subsection{Acceptance Model}

Venkatesh et al.'s (2003) Unified Theory of Acceptance and Use of Technology (UTAUT) is a common model that is frequently used in the ICT field. Masrom and Hussein (2008) propose that as much as 70\% of conduct in relation to technology acceptance could be described by UTAUT. Venkatesh et al. (2003) explain that enabling variables directly affecting a potential users' intent, social variables, views on simplicity of utilisation in the form of effort expectancy, as well as views on utility in the form of performance expectancy, are the four major aspects of UTAUT. Furthermore, Venkatesh et al. believe that the models' major interactions can be influenced 
by independent choice, experience, age, and sex.

\subsection{Studies Related to Mobile Learning}

Al-Zahrani (2015) argue that positive alterations in the educational context that would result from mobile learning must be outlined to both educators and learners, in order for its successful implementation. The application of mobile learning should be embraced by teachers, regardless of certain obstacles, because the international spread of mobile devices is likely to be an ongoing process. The acquisition of capabilities and learning that takes place throughout life can be facilitated by the utilisation of mobile learning, which is one of its major advantages according to studies, despite further empirical investigations being necessary (Laxman, 2012). The teaching and educational methods that must alter to implement mobile learning should be comprehended by educators, as well as their receiving training on adept use of the technology, in order to fully realise mobile learning's potential. Consequently, mobile learning's understanding by educational facilities and educators in relation to academic changes should receive greater focus. Berking et al. (2012) propose that carefully tailored teaching processes must accompany mobile learning methods, so as to achieve the utmost success from them.

Research was conducted in 2009 by Birch and Irvine, consisting of a sample of 82 participants from Canadian universities. The majority were males under 30. Cronbach's alpha was used for the analysis. The aim of this study was to explore the factors which influence the acceptance of teachers' preservation of ICT integration in the classroom. The results show that effort expectancy was the only significant predictor of behaviour intention.

Dulle and Minishi-Majanja (2011) utlised the UTAUT to examine students' adaptation of technology in the public universities of Tanzania. The use and adoption of open access were analysed. A questionnaire with a stratified random sample, which consisted of 544 respondents selected from six public universities, was conducted. For the statistical analysis, binary logistic regression statistics were used. According to the research, it was determined that the UTAUT model is supported in the scholars' environment in the study of open access. It was also found that the key factors were the awareness, attitude, and duration of productive effort. The importance of this research consists in determining the behavioural intentions of researchers. Moreover, as a result of the study, it was defined that the level of awareness, social influence, age, and behavioural intentions significantly affect the actual use of open access.

Since the researchers of social media have become a frequent occurrence in recent years, the researchers and instructors now increasingly use these tools for professional work. Gruzd, Staves and Wilk (2012) investigated why and how they use a variety of social media for the proliferation of information and communication. For the analysis, 51 semi-structured interviews with instructors were used. The Unified Theory of Acceptance and Use of Technology was used to analyse the coded transcripts. The research is very important to the presented work, as it was directed not only to determine the implemented specific tools, but also the factors that affect the intention to use social media as an educational tool.

Cultural differences might influence the adaptation and use of technology. For that reason, Im, Hong and Kang (2011) collected data from the US and Korea in order to investigate the relationship in UTAUT design model and to determine their effect on culture. The UTAUT measurement instruments were valid across multiple cultures and were measured using a seven-point Likert scale. Moreover, for the analysis, Cronbach's alpha and confirmatory factor analysis were used. In the American sample, the effect of behavioural intentions and expectations were higher than in the Korean sample. Therefore, the importance of the article presented above is the determination of the influence of cultural factors.

Magsamen-Conrad et al. (2015) explored the use of tablet devices across generations employing the Unified Theory of Acceptance and Use of Technology as a theoretical guide of the exploration. In this research, four UTAUT determinants were tested to determine their predicting possibilities for behavioural intention: social influence, performance expectancy, facilitating conditions and effort expectancy. The sample contained 899 respondents from 19 to 99 years old. For analysis, factor analysis (varimax) and scree plot were used. The results show that facilitating conditions and effort expectancy were the only determinants, which positively predicted tablet use. Gender and age were insignificant. Moreover, ageism and gender discrimination were provided.

Taiwo and Downe (2013) conducted a meta-analysis of 37 separate empirical studies. The study determined that the relationship between the duration of execution of the behavioural purpose is quite strong. It is very important for this work, as it explores and combines the existing empirical literature about the Unified Theory of Acceptance and Use of Technology. It gave the opportunity to explore a sample of more than 11,000 respondents. The analysis of statistical data was provided in two phases. The first phase was the sample correlation, and the second was the computation of the correlation's univariate analysis. Moreover, this research contributes to IS/IT 
diffusion and acceptance studies, showing an inconsistent and inadequate use of conclusions.

Tandi and Questier (2014) conducted a study that aimed to investigate factors which affect the use and adoption of open access in the health science universities of Tanzania. The sample included 415 faculty members. A cross-sectional questionnaire survey was provided through stratified random sampling. The analysis was made through binary logistic regression. The results have shown that the actual usage of open access can be predicted through the extrinsic benefits, behavioural intention, facilitating conditions and individual characteristics. Similarly, Teo (2011) examined the factors which explain the intention of teachers to use technology and to develop a model that can be used to the statistical explanation of the interactions among them. The sample included 592 schoolteachers from Singapore. Structural equation modelling, model testing, and parameter estimation were used for the analysis. The results found a good model fit. The subjective norm had insignificant influence on the intention of teachers to use the technology.

Venkatesh et al. (2011) conducted a study that presents the expansion of two-stage theories of expectations confirmation in the standing information systems. First, in this research the predictors were used, which are present in the UTAUT, namely the social impact, the duration of effort, and favourable conditions. Second, the IS continuance model also includes the transfer of confidential information as a core belief. For this research, a longitudinal study with 3159 residents of Hong Kong was carried out. For the analysis, confirmatory factor analysis was used on each sample. It is an important resource because it shows how the predictors, identified in UTAUT, influence the formation and change settings on the IS continuance intention.

Wang, Wu, and Wang (2009) investigated the factors that affect user intention to utilise mobile learning. The Unified Theory of Acceptance and Use of Technology made it possible to determine the adoption of this type of training and discover its relationship to gender and age. The sample contained 330 respondents from Taiwan through the equation method of structural modelling. During this study, it was also found that age and gender differences soften the effects of social influence and effort expectancy on mobile learning use. For the analysis, confirmatory factor analysis was used. The study is important for the present article, as it shows that the determining factors in the intention to use mobile learning are social influence, playfulness, duration of effort and performance.

\subsection{The Study Question}

This study attempts to address the following question: Are the following independent variables significant predictors of the instructors' behavioural intention to use mobile learning at KSA universities: performance expectancy, effort expectancy, social influence, and facilitating conditions?

\section{Method}

\subsection{Population and Sampling}

The target population of this study is the faculty members of Hail University, which is a public university in northern Saudi Arabia. Hail University was recently established in 2006 and has a deanship of e-learning and distance education. Convenience sampling, which is a non-random sampling technique, was used to select a sample from the population. Convenience sampling was utilised because a reliable random sampling frame was not available for the researchers. The data collection process took place in the autumn semester of 2016. A link to the online survey was distributed to 120 faculty members to collect data, and 83 participants returned the survey with response rate of $69 \%$. However, three participant responses were not included in the data analysis due to incomplete answers. Thus, valid responses from 80 participants were included and used in the analysis process.

\subsection{Instruments}

The instrument of this study was adapted from the UTAUT questionnaire (Venkatesh et al., 2003). The UTAUT questionnaire is commonly used and frequently validated (Alawadhi \& Morris, 2008). For instance, Al-Hujran (2014) reported the Cronbach's alpha of all UTAUT scales ranged from 0.83 to 0.92 , which indicate the reliability of the measurement scales. The instrument of this study consists of two main sections. The first section measures instructors' demographic information, while the second section measures the core constructs of UTAUA, namely performance experience (PE), effort expectancy (EE), social influence (SI) facilitating conditions (FC), and behavioural intention (BI). The instrument's items were measured using a five-point Likert scale, ranging from 1 indicating 'strongly disagree' to 5 indicating 'strongly agree'.

\section{Results}

\subsection{Participant Profile}

The results of descriptive statistics indicated that $60 \%$ of the participants were male, and $40 \%$ were female. The 
age of the participants ranged from $25-62$ years old, with $65 \%$ between $31-57$ years old. Nearly $29 \%$ of the participants had teaching experience of 1-5 years. Participants with 6-10 years of teaching experience represents $25 \%$ of the sample, while about $16 \%$ of the participants taught between $11-15$ years. Only $12.5 \%$ had teaching experience between 16-20 years and $17.5 \%$ above 20 years of teaching at university level. In terms of the participants' familiarity and experience with mobile technology, only $8.8 \%$ of the participants evaluated themselves as below average or novice users of mobile technology. Most of the participants were average (33.8\%), above average (25\%), or expert (32.5\%) users of mobile devices (see Table 1$)$.

Table 1. Sample characteristics

\begin{tabular}{llll}
\hline Measure & Item & Frequency & Percentage (\%) \\
\hline \multirow{3}{*}{ Gender } & Male & 48 & 60 \\
& Female & 32 & 40 \\
& $1-5$ & 23 & 28.7 \\
Teaching Experience & $6-10$ & 20 & 25 \\
& $11-15$ & 13 & 16.3 \\
& $16-20$ & 10 & 12.5 \\
& Above 20 & 14 & 17.5 \\
& Novice & 1 & 1.3 \\
Mobile Technology Expertise & Below Average & 6 & 7.5 \\
& Average & 27 & 33.8 \\
& Above Average & 20 & 25 \\
& Expert & 26 & 32.5 \\
\hline
\end{tabular}

\subsection{Measurement Validity and Reliability}

The instrument validity was established by examining the instrument content validity, which is "a qualitative type of validity where the domain of the concept is made clear and the analyst judges whether the measures fully represent the domain" (Bollen, 1989, p.185). A panel of experts in educational and mobile technology were asked to provide their feedback on the accuracy of the instrument items in measuring the UTAUT constructs, including performance expectancy, effort expectancy, social influence, and facilitating conditions. They provided their evaluation by rating how well the wording of each item in the instrument measures each construct. The evaluation of each expert was compared to determine the level of survey content validity. Based on the expert evaluations, a few changes were made to the survey's wording to yield the highest level of survey content validity.

The instrument reliability was established through the calculation of Cronbach's alpha to determine the internal consistency reliability of each UTAUT scale. Cronbach's alpha is a test reliability technique that ranges between 0 and 1 . The items in a scale represents a great level of internal consistency when the Cronbach's alpha coefficient is closer to 1.0 (Gliem \& Gliem, 2003). The results of Cronbach's alpha of the UTAUT scales in this study ranged between 0.77 to .92 , indicating an acceptable to excellent reliability for each scale based on the rules of thumb given by George and Mallery (2003) (see Table 2).

Table 2. Cronbach's alpha inter

\begin{tabular}{lll}
\hline Constructs & Number of Item & Cronbach's Alpha \\
\hline EP & 4 & 0.92 \\
EE & 4 & 0.91 \\
SI & 4 & 0.82 \\
FC & 3 & 0.77 \\
BI & 3 & 0.90 \\
\hline
\end{tabular}

\subsection{The Regression}

A simple linear regression was preformed to address the first question and determine whether the age of the instructors was significantly associated to their intention to adapt and use mobile technology in their teaching. Prior to preforming the regression analysis, basic assumptions of the regression analysis, including normality, 
multicollinearity, and linearity were examined. Data normality was examined by conducting a Skewness and Kurtosis test. If the Skewness and Kurtosis value of each scale ranges between \pm 2.00 at $p<-0.01$, then the data are considered normally distributed (Field, 2009). The results of analysis showed that all UTAUT constructs took place in the acceptable range of the Skewness and Kurtosis test, indicating that the data are normally distributed (see Table 3).

Table 3. Means, standard deviations, and normality test

\begin{tabular}{lllll}
\hline Construct & Skewness & Kurtosis & Mean & SD \\
\hline EP & -0.401 & -0.930 & 3.60 & 0.101 \\
EE & -0.423 & -1.090 & 3.67 & 0.109 \\
SI & 0.121 & -0.756 & 3.12 & 0.086 \\
FC & 0.475 & -0.338 & 2.95 & 0.087 \\
BI & -0.455 & -0.974 & 3.45 & 0.121 \\
\hline
\end{tabular}

The Tolerance and Variance Inflation Factors (VIF) were examined to assess the multicollinearity, which exists when two or more constructs or predictors are highly correlated in a regression model. The multicollinearity does not exist in a regression model when the Tolerance value is greater than 0.1 and the VIF value is less than 10 (Field, 2009). The results of the Tolerance and VIF indicated that all Tolerance values surpassed the 0.1 constraint, and the VIF values were less than 10 for all UT constructs (see Table 4). Thus, the assumption of absence of multicollinearity was met.

Table 4. Multicollinearity test

\begin{tabular}{lll}
\hline Construct & Tolerance & VIF \\
\hline PE & 0.358 & 2.793 \\
EE & 0.309 & 3.236 \\
SI & 0.458 & 2.183 \\
FC & 0.547 & 1.829 \\
\hline
\end{tabular}

The residual plots were utilised to examine linearity assumption, which indicates that the relationship between independent and dependent variables is linear. The results of the standardised residual plots indicated that the linearity assumption was met and heteroscedasticity does not exist. The standardised residual was also utilised to check for outliers. A standardised residual value greater than 3 is considered an outlier in regression analysis. The residual plots did not show any outlier.

In order to address the study's question, standard multiple regression was employed to determine if performance experience (PE), effort expectancy (EE), social influence (SI), and facilitating conditions (FC) statistically significantly predicted behavioural intention (BI). Table 4 shows all means, standard deviations, and intercorrelations between outcome and predictor variables. As can be seen in Table 5, all variables were positively related to each other. For instance, performance experience (PE) was positively related to behavioural intention $(\mathrm{BI})(r=0.743, p=0.01)$. See Table 5 for more details.

Table 5. UTAUA constructs correlations

\begin{tabular}{|c|c|c|c|c|c|c|c|}
\hline Variables & Mean & SD & BI & PE & EE & SI & $\mathrm{FC}$ \\
\hline BI & 3.45 & 0.121 & 1 & & & & \\
\hline PE & 3.60 & 0.101 & $0.743^{* *}$ & 1 & & & \\
\hline $\mathrm{EE}$ & 3.67 & 0.109 & $0.790 * *$ & 0.790 ** & 1 & & \\
\hline SI & 3.12 & 0.086 & $0.618^{* *}$ & $0.625^{* *}$ & $0.665^{* *}$ & 1 & \\
\hline $\mathrm{FC}$ & 2.95 & 0.087 & $0.561 * *$ & $0.520 * *$ & $0.600 * *$ & $0.627 * *$ & 1 \\
\hline
\end{tabular}

The analysis shows the unstandardised regression coefficients (B) which can be used to predict behavioural intention for a participant, the standardised regression coefficient $(\beta)$, which determines the relative importance 
of the four predictors: performance experience (PE), effort expectancy (EE), social influence (SI), and facilitating conditions (FC). The partial and semi-part correlations, zero-order correlations, $\mathrm{R}^{2}$ which is used to examine the relationship between the predictor variables and the dependent variables.

Table 6. Multiple regression model

\begin{tabular}{llll}
\hline R Square & Adjusted Rs & F Value & P Value \\
\hline 0.67 & 0.65 & 38.652 & $0.000^{* * *}$ \\
\hline
\end{tabular}

$\mathrm{R}$ for regression was statistically different from zero, $\mathrm{F}(4,75)=38.652, \mathrm{p}=.001$, with $\mathrm{R}^{2}$ at 0.67 ( 0.65 adjusted) indicates that over $67 \%$ of the variation in the BI is predicted by performance experience, effort expectancy, social influence, and facilitating conditions all together (see Table 6). Based on standardised regression coefficients and t-scores, it was revealed that $\mathrm{PE}(\beta=.287, \mathrm{p}<.01)$ and $\mathrm{EE}(\beta=.453, \mathrm{p}<.001)$ are significant predictors of BI. However, SI $(\beta=.453)$ and $\mathrm{FC}(\beta=.453)$ are not significant predictors of $\mathrm{BI}$ of the use of mobile learning at $\mathrm{p}<.05$. In addition, It would appear that $\mathrm{EE}$ was the best predictor of the $\mathrm{BI}(\beta=.453, \mathrm{p}<.001)$. EE is the most important variable based on the squared semi-partial correlations, partial correlations, and zero-order correlations (see Table 7).

Table 7. Regression analysis summary

\begin{tabular}{lllllllll}
\hline Variables & $\mathrm{B}$ & $\mathrm{SE} \mathrm{B}$ & $\beta$ & $\mathrm{T}$ & $\mathrm{P}$ & Zero-Order & Partial & Part \\
\hline PE & .339 & .135 & .287 & 2.505 & .015 & .745 & .289 & .172 \\
EE & .499 & .138 & .453 & 3.603 & .001 & .791 & .398 & .247 \\
SI & .151 & .147 & .104 & 1.024 & .309 & .632 & .122 & .070 \\
FC & .096 & .132 & .067 & .733 & .466 & .552 & .088 & .050 \\
\hline
\end{tabular}

$R^{2}=0.67(\mathrm{n}=80, \mathrm{p}<.001)$

\section{Discussion}

The purpose of the study was to examine the factors that influence university instructors' behavioural intention to use mobile learning in KSA. This study utilised UTAUA as a theoretical framework. The constructs of UTAUA including performance expectancy, effort expectancy, social influence, and facilitating conditions were used as a predictors of instructors' behaviour influence to use mobile learning. The findings of this study revealed that PE and EE were significant predictors of Saudi instructors' behavioural intention to use mobile learning at higher education whereas SI and FC were not significant predictors of instructors' behavioural intention to use mobile learning. These findings are consistent with several studies in the literature. Performance expectance, which refers to the beliefs that instructors possess about the benefits and usefulness of using mobile learning in teaching and learning, was a strong and significant predictor of the intention to use mobile learning. Similarly, existing studies support this result.

For instance, Nassuora (2012) examined the factors that affect students' intention to use mobile learning and found a positive relationship between performance expectancy and students' intentions to use mobile learning. This finding has an important implication on use and implementation of mobile learning in teaching and learning. As an imperative step in designing and implementing mobile learning, universities should emphasise the importance of the expected benefits and usefulness of mobile learning among instructors. This can be accomplished through conducting workshops that illustrate the advantages of using mobile learning, including flexibility, improved retention, and time efficiency. This step should take place before the implementation of mobile learning in any educational institution which will prepare instructors to successfully use and apply mobile learning. Due to raised awareness of the usefulness of mobile learning among teachers, the intention to use mobile learning will increase and the probability of having effective implementation of mobile learning will expand.

Effort expectancy, which is the degree of ease related to the use of mobile learning in teaching and learning, was a strong and significant predictor of instructors' behavioural intention to use mobile learning at the university level. This finding is consistent with the finding of Birch and Irvine's (2009) study in which effort expectancy has a positive relationship with teachers' intention to use technology in the classroom. Moreover, effort expectancy was the only significant predictor of teachers' intention to utilise technology in their instruction. This is also an important finding that can impact the design and implementation of mobile learning in higher education. 
Universities should apply interventions in order to increase instructors' effort expectancy. In other words, university instructors should be trained in using mobile learning in the teaching process. They can experience, through these training sessions, the ease of using mobile learning in teaching and learning. Therefore, the mobile learning tools and services should be developed to be user friendly. Instructors do not have to be tech savvy to use mobile learning. Universities should ensure mobile learning system is simple and easy to use.

The findings of this study also revealed that social influence and facilitating conditions were not significant predictors of instructors' behavioural intention to use mobile learning. These findings are consistent with existing literature (e.g., Birch \& Irvine, 2009; Nassuora, 2012). However, these findings contradicted other studies that found social influence to be a significant predictor of students' intention to use mobile learning (Al-Hujran, Al-Lozi, \& Al-Debei, 2014) and facilitating conditions to have a positive relationship with the intention to use mobile learning (Carter et al., 2012). The inconsistent findings in the literature regarding these two UTAUA constructs, social influence and facilitating conditions, requires more research to examine their influence on instructors' intention to use mobile learning in teaching and learning.

\section{Conclusion}

The Kingdom of Saudi Arabia has seen a considerable expansion in the utilisation of mobile devices. The country's educational environment stands to be significantly improved through mobile learning methods. In order for mobile learning to be successfully developed and applied, it is crucial to consider both educators' and learners' perspectives on the concept. University-level learners have been the focus for the majority of existing mobile learning research. Consequently, contributing to a better understanding of higher education educators' perspectives of mobile learning was the objective of this research. Hail University was the location of the tutors approached, whose behavioural intent for applying mobile learning was assessed with respect to variables impacting upon their choices. An estimation of tutors' behavioural intent was undertaken through application of the UTAUA model, which also acted as the theoretical basis of this research and has been widely applied in the literature.

Hail University tutors' behavioural intent in applying mobile learning was not seen to be meaningfully affected by facilitating conditions and social influence, whereas a significant relationship was found to effort expectancy and performance expectancy. The population sample utilised in this research may explain the discrepancy with existing research, which has typically found the UTAUA variables of facilitating conditions and social influence as affecting behavioural intent. This is because university-level educators' opinions were being investigated rather than learners, as in the majority of previous research. Consequently, a random sampling method focused on a bigger population should form the basis of future studies into mobile learning and tutor acceptance.

\section{References}

Al-Hujran, O., Al-Lozi, E., \& Al-Debei, M. M. (2014). Get Ready to Mobile Learning”: Examining Factors Affecting College Students' Behavioral Intentions to Use M-Learning in Saudi Arabia. Jordan Journal of Business Administration, 10(1).

Birch, A., \& Irvine, V. (2009). Preservice Teachers' Acceptance of ICT Integration in the Classroom: Applying the UTAUT Model. Educational Media International, 46(4), 295-315. https://doi.org/10.1080/09523980903387506

Cheung, W. S., \& Hew, K. F. (2009). A Review of Research Methodologies used in Studies on Mobile Handheld Devices in K-12 and Higher Education Settings. Australasian Journal of Educational Technology, 25(2), 153-183. https://doi.org/10.14742/ajet.1148

Dulle, F. W., \& Minishi-Majanja, M. K. (2011). The Suitability of the Unified Theory of Acceptance and Use of Technology (UTAUT) Model in Open Access Adoption Studies. Information Development, 27(1), 32-45. https://doi.org/10.1177/0266666910385375

eMarketer. (2015). Smartphones, Tablets Spread across the Middle East and Africa. Retrieved February 3, 2016, from http://www.emarketer.com/Article/Smartphones-Tablets-Spread-Across-Middle-East-Africa/1012989.

Gliem, R. R., \& Gliem, J. A. (2003). Calculating, interpreting, and reporting Cronbach's alpha reliability coefficient for Likert-type scales. Midwest Research-to-Practice Conference in Adult, Continuing, and Community Education.

Gruzd, A., Staves, K., \& Wilk, A. (2012). Connected scholars: Examining the Role of Social Media in Research Practices of Faculty using the UTAUT Model. Computers in Human Behavior, 28(6), 2340-2350. https://doi.org/10.1016/j.chb.2012.07.004

Im, I., Hong, S., \& Kang, M. S. (2011). An International Comparison of Technology Adoption: Testing the 
UTAUT Model. Information \& Management, 48(1), 1-8. https://doi.org/10.1016/j.im.2010.09.001

Kennedy, G. E., Judd, T. S., Churchward, A., \& Gray, K. (2008b). First Year Students' Experiences with Technology: Are They Really Digital Natives? Australasian Journal of Educational Technology, 24(1), 108-122. https://doi.org/10.14742/ajet.1233

Magsamen-Conrad, K., Upadhyaya, S., Joa, C., \& Dowd, J. (2015). Bridging the Divide: Using UTAUT to Predict Multigenerational Tablet Adoption Practices. Computers in Human Behavior, 50, 186-196. https://doi.org/10.1016/j.chb.2015.03.032

Masrom, M., \& Hussein, R. (2008). User acceptance of information technology: Understanding theories and model. Venton Publishing: Kuala Lumpur, Malaysia.

Ministry of Education. (2016). Higher Education in Saudi Arabia.

Nassuora, A. B. (2012). Students' Acceptance of Mobile Learning for Higher Education in Saudi Arabia. American Academic \& Scholarly Research Journal, 4(2), 24-30.

Quality Improvement Agency. (2010). Mobile learning: What is mobile learning? Retrieved Jan, 10, 2012, from http://www.excellencegateway.org.uk/page.aspx?o=135556

Taiwo, A. \& Downe, A. (2013). The Theory of User Acceptance and Use of Technology (UTAUT): A Meta-Analytic Review of Empirical Findings. Journal of Theoretical and Applied Information Technology, 49(1), 48-58.

Tandi Lwoga, E. \& Questier, F. (2014). Faculty Adoption and Usage Behaviour of Open Access Scholarly Communication in Health Science Universities. New Library World, 115(3/4), 116-139. https://doi.org/10.1108/NLW-01-2014-0006

Teo, T. (2011). Factors Influencing Teachers' Intention to Use Technology: Model Development and Test. Computers \& Education, 57(4), 2432-2440. https://doi.org/10.1016/j.compedu.2011.06.008

Venkatesh, V., Morris, M. G., Davis, G. B., \& Davis, F. D. (2003). User Acceptance of Information Technology: Toward a Unified View. MIS Quarterly, 425-478.

Venkatesh, V., Thong, J., Chan, F., Hu, P., \& Brown, S. (2011). Extending the Two-stage Information Systems Continuance Model: Incorporating UTAUT Predictors and the Role of Context. Information Systems Journal, 21(6), 527-555. https://doi.org/10.1111/j.1365-2575.2011.00373.x

Wang, Y., Wu, M., \& Wang, H. (2009). Investigating the Determinants and Age and Gender Differences in the Acceptance of Mobile Learning. British Journal of Educational Technology, 40(1), 92-118. https://doi.org/10.1111/j.1467-8535.2007.00809.x

\section{Copyrights}

Copyright for this article is retained by the author(s), with first publication rights granted to the journal.

This is an open-access article distributed under the terms and conditions of the Creative Commons Attribution license (http://creativecommons.org/licenses/by/4.0/). 